\title{
ELECTRON SPECTROSCOPY OF CdMeTe NANOSTRUCTURES CREATED ON CdTe SURFACE UNDER ION BOMBARDMENT
}

\author{
Ergashov Yokub ${ }^{1, *}$, and Umirzakov Boltakhodja ${ }^{1}$ \\ ${ }^{1}$ Tashkent State Technical University, 100095, 2-University street, Tashkent, Uzbekistan
}

\begin{abstract}
The electronic structure of CdMeTe nanostructures was studied by a variety of techniques of secondary and photoelectron spectroscopy. Particularly, for the first time it has been shown that in the conductivity band of the CdZnTe films there are maximums peaks of free electronic states with energies 3.5 and $4.4 \mathrm{eV}$ relative $\mathrm{E}_{\mathrm{v}}$.
\end{abstract}

\section{Introduction}

Multi-layer thin-film structures based on semiconductor compounds $\mathrm{A}^{2} \mathrm{~B}^{6}$ are widely used to design diverse optoelectronic devices, including solar cells. We have investigated crystalline structure of CdTe, CdZnTe and $\mathrm{HgCdTe}$ films, as well as their optical properties and how they change under different influences [1-6]. It was shown that properties of these films mainly depend on a synthesis technique, on their thickness and properties of a near-contact (transitive) layer formed on the boundary film-substrate. In recent years a techniques of lowenergy ion implantation is frequently used for nano-sized structures on the surface and in near-surface region of semiconductor and dielectric films [7-10]. Particularly, the films of $\mathrm{Cd}_{0.5} \mathrm{Ba}_{0.5} \mathrm{Te}$ were produced by the $\mathrm{Ba}^{+}$ion implantation into CdTe in combination with annealing [10]. It was established that the state densities of valence electrons and the forbidden band width of the CdBaTe nanofilms for $\mathrm{d} \leq 25-30 \AA$ depend on film thickness.

This paper reports the energy band parameters and the results of the studyof the density of electronic states in the valence band and in the conductivity band for three-component nanofilms of $\mathrm{Cd}_{1-\mathrm{x}} \mathrm{Me}_{\mathrm{x}} \mathrm{Te}$ produced by $\mathrm{Ba}$ and $\mathrm{Zn}$ ion implantation into CdTe.

\section{Experimental methods}

Single crystalline $\mathrm{CdTe}(100)$ of the n-type with the sizes $10 \times 10 \times 1 \mathrm{~mm}^{3}$ were polished and treated with an etchant. The investigation was carried out in vacuum $\left(10^{-6}\right.$ bar) by Auger-electron spectroscopy (AES), ultraviolet photoelectron spectroscopy (UPS), electron energy loss spectroscopy (EELS) and by measurements of energy dependencies of the coefficients of secondary electron emission (SEE) and intensities of light transmitting through the sample. Morphology and degree of surface roughness were studied by scanning electron microscopy (SEM) and atomic force microscopy (AFM). The profiles of atom distributions in depth were defined by AES in combination with ion etching.Ion bombardment was made perpendicular to the target surface under vacuum $\left(10^{-6}\right.$ bar $)$. Before ion implantation the CdTe samples were degassed by heating up to $\mathrm{T}=1100 \mathrm{~K}$ in combination with mild etching with the $\mathrm{Ar}^{+}$ ions under vacuum $\left(10^{-7} \mathrm{bar}\right)$. By varying energy of the $\mathrm{Ba}^{+}$and $\mathrm{Zn}^{+}$ions within the range $0.5-5 \mathrm{keV}$ the threecomponent nanoscale structures with the thickness 20-50 $\mathrm{nm}$ were produced. The optimal modes of ion implantation and annealing for the nanocrystals (NC) and nanofilms (NF) of $\mathrm{CdMeTe} / \mathrm{CdTe}(100)$ are presented in Table 1.

Table 1. Optimal modes of formation of three-component nanostructures of $\mathrm{CdMeTe} / \mathrm{CdTe}(100)$.

\begin{tabular}{|c|c|c|c|c|c|c|}
\hline Ions & $\mathrm{E}_{0}, \mathrm{keV}$ & $\mathrm{D}, \mathrm{cm}^{-2}$ & $\mathrm{~T}_{0}, \mathrm{~K}$ & Structure & $\begin{array}{c}\text { Approximate } \\
\text { composition }\end{array}$ & $\begin{array}{c}\text { Film } \\
\text { thicknessd, } \AA\end{array}$ \\
\hline \multirow{2}{*}{$\mathrm{Ba}$} & 1 & $10^{15}$ & 900 & $\mathrm{NC}$ & $\mathrm{Cd}_{0.6} \mathrm{Ba}_{0.4} \mathrm{Te}$ & $35-40$ \\
& & $6 \cdot 10^{16}$ & 1000 & $\mathrm{NF}$ & $\mathrm{Cd}_{0.5} \mathrm{Ba} 0.5 \mathrm{Te}$ & $35-40$ \\
\cline { 2 - 7 } & 3 & $10^{15}$ & 900 & $\mathrm{NC}$ & $\mathrm{Cd}_{0.7} \mathrm{Ba} a_{0.3} \mathrm{Te}$ & $50-60$ \\
& & $8 \cdot 10^{16}$ & 1000 & $\mathrm{NF}$ & $\mathrm{Cd}_{0.5} \mathrm{Ba} 0.5 \mathrm{Te}$ & $50-60$ \\
\hline \multirow{2}{*}{$\mathrm{Zn}$} & 1 & $10^{15}$ & 850 & $\mathrm{NC}$ & $\mathrm{Cd}_{0.6} \mathrm{Zn} 0.4 \mathrm{Te}$ & $40-45$ \\
\cline { 2 - 7 } & 1 & $8 \cdot 10^{16}$ & 800 & $\mathrm{NF}$ & $\mathrm{Cd}_{0.7} \mathrm{Zn} 0.3 \mathrm{Te}$ & - \\
\hline
\end{tabular}

\footnotetext{
* Corresponding author: yergashev@ rambler.ru
} 


\section{Results and discussion}

The photoelectron spectra of pure $\mathrm{CdTe}(100)$ and $\mathrm{CdTe}(100)$ with the $\mathrm{Cd}_{0.6} \mathrm{Zn}_{0.4} \mathrm{Te}$ film which were measured for $h v=10.8 \mathrm{eV}$ are presented in Fig.1. The spectral structure, i.e. the density of valence electron states of matrix and film, greatly differ from each other. The peaks corresponding to $\mathrm{E}_{1}, \mathrm{E}_{2}$ and $\mathrm{E}_{3}$ in the $\mathrm{CdTe}$ spectrum can be associated with hybridization of the $5 \mathrm{p}$ and $5 \mathrm{~s}$ electrons of Te with the $5 \mathrm{~s}$ and $4 \mathrm{~d}$ ones of $\mathrm{Cd}$. In the case of a three-component film, along with the $\mathrm{Cd}$ and $\mathrm{Te}$ electrons the $3 \mathrm{~d}$ and $4 \mathrm{~s}$ electrons of $\mathrm{Zn}$ will participate in electron hybridization owing to which the re-distribution of the density of valence electron states takes place. Besides these peaks, in the spectra there are peaks associated with the surface states $\left(E_{s s}\right)$ and impurity levels $\left(E_{i m p}\right)$. The spectrum width $\Delta \mathrm{E}$ of film is $0.2-0.3 \mathrm{eV}$ less than that of matrix.

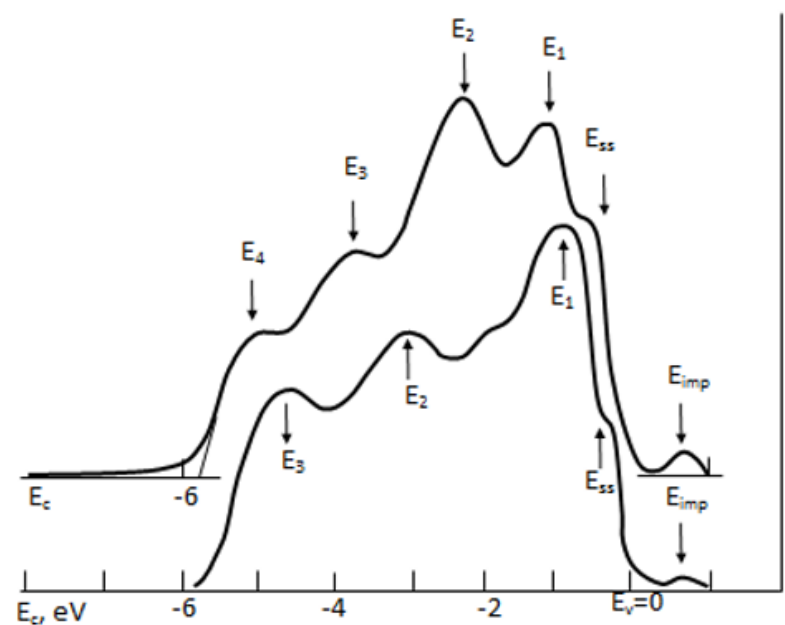

Fig. 1. The photoelectron spectra of pure CdTe (100) and with $\mathrm{Cd}_{0.6} \mathrm{Zn}_{0.4} \mathrm{Te}$ nanofilm for $\mathrm{hv}=10.8 \mathrm{eV}$.

The spectra $\mathrm{N}\left(\mathrm{E}_{2}\right)$ measured for $\mathrm{E}_{\mathrm{p}}=5 \mathrm{eV}$ for pure CdTe and for CdTe with a submonolayer Cs film $(\theta \approx 0.2)$ are presented in Fig.2. $E_{2}$ is the energy of secondary electrons. Zero on the $E_{2}$ axis corresponds to a vacuum level of the CdTe film. From Fig. 3 it is seen that after Cs deposition the emission of true-secondary electrons into vacuum increases and the spectrum start sifts to lower energy by $\sim 2.6 \mathrm{eV}$, i.e. the potential barrier (electron affinity $\chi$ ) decreases by $2.6 \mathrm{eV}$. In this part of the spectrum there are peculiarities for energy $\mathrm{Ec}_{1}=-1$ and $\mathrm{E}_{\mathrm{c} 2}=-1.9 \mathrm{eV}$ (relative to $\mathrm{E}_{\mathrm{v}}$ for energy 3.5 and 4.4 $\mathrm{eV}$ ). The positions of these peculiarities correspond to maximums of the density of electronic states in the conductivity band. By increasing the thickness of the Cs film up to $0.5-0.6$ in the monolayer it is possible to decrease $\chi$ by $\sim 3-3.5 \mathrm{eV}$. However, beginning with $\theta \sim 0.4-0.5$ of monolayers, in the spectrum there are peculiarities associated with the Cs atoms.

The dependences of true-secondary electrons $\delta$, elastically reflected ones $\chi$ and $\mathrm{dR} / \mathrm{dE}_{\mathrm{p}}$ on primary electron energy $E_{p}$ for $\operatorname{CdTe}(111)$ within the range of $E_{p}=0-20 \mathrm{eV}$ are presented in Fig.3. The peculiarities of the curve $R\left(E_{p}\right)$, i.e. maximums of the curves $\mathrm{dR} / \mathrm{dE}_{\mathrm{p}}\left(\mathrm{E}_{\mathrm{p}}\right)$, correspond to the electron transitions from the valence band maximums into the conductivity zone maximums [11]. Analysis of the $\mathrm{dR} / \mathrm{dE}_{\mathrm{p}}\left(\mathrm{E}_{\mathrm{p}}\right)$ curve (spectra of elastically reflected electrons) for photoelectrons (Fig.1) and true-secondary electrons showed that the maximum $\mathrm{E}_{1}{ }^{\prime}$ corresponds to the electron transition from $E_{v}$ to $E_{c}$ (approximately equal to $\left.E_{\mathrm{g}}\right) ; \mathrm{E}_{2}{ }^{\prime}$ to the transition from $\mathrm{E}_{1}$ to $\mathrm{E}_{\mathrm{c} 1} ; \mathrm{E}_{3}{ }^{\prime}$ to the transition from $E_{v}$ to $E_{2}$; and $E_{4}{ }^{\prime}$ to the transition from $E_{2}$ to $\mathrm{E}_{\mathrm{c} 2}$. The maximums $\mathrm{E}_{6}{ }^{\prime}$ and $\mathrm{E}_{7}{ }^{\prime}$ can be probably associated with the electron transition from the maximums of the density of the valent electron states into the maximum of free states in vacuum. The position $\mathrm{E}_{3}{ }^{\prime}$ corresponds to an initial immediate increase in $\delta$, which is due to the electron transition from the top of the valent zone into vacuum. For $\mathrm{E}_{\mathrm{p}}=11.2 \mathrm{eV}$ there is also an immediate decrease in $\mathrm{R}$ (maximum on the curve $\mathrm{dR} / \mathrm{dE}_{1}$ ). However, for this energy $E_{p}$ there is no immediate increase in $\delta$. Owing to the above statements it is possible to suppose that the valence electrons move not to vacuum but to a maximum of the conductivity band. For the width of the forbidden band of CdTe to be defined more accurately, the energy dependence of the intensity I of light transmitting through CdTe was measured within the range $h v=0.6-2 \mathrm{eV}$ [10]. From Fig.4 it is seen that for $\mathrm{CdTeE}_{\mathrm{g}}$ is $\sim 1.45 \mathrm{eV}$.

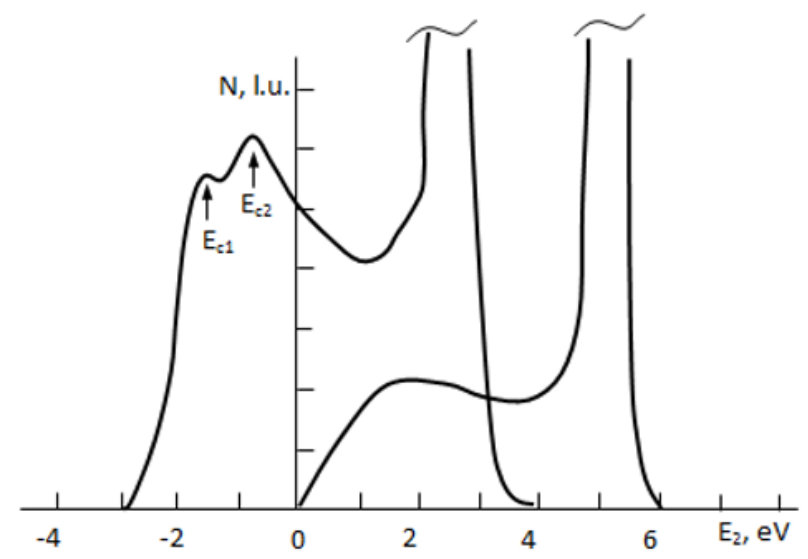

Fig. 2. The spectra $\mathrm{N}\left(\mathrm{E}_{2}\right)$ measured for $\mathrm{E}_{\mathrm{p}}=5 \mathrm{eV}$ for pure $\mathrm{CdTe}$ and $\mathrm{CdTe}$ with the submonolayer $(\theta \approx 0.2)$ film of Cs.

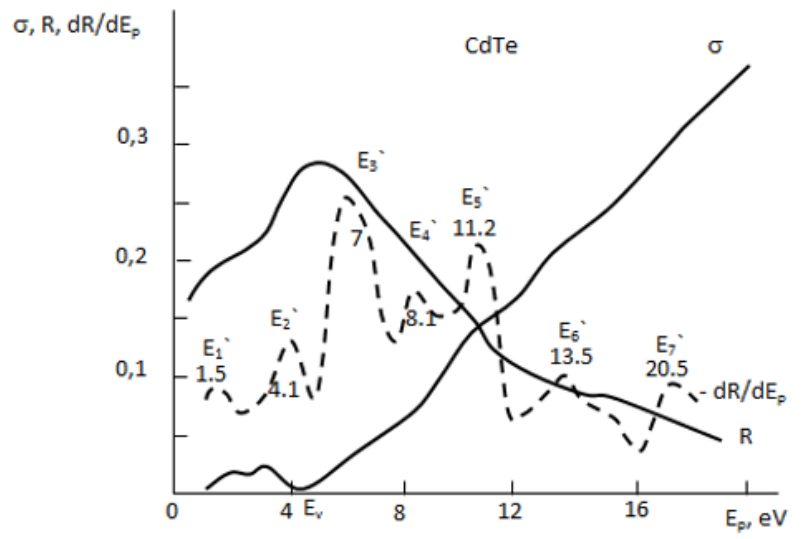

Fig. 3. The dependences of $\delta$, Rand - $d R / d E_{p}$ on energy of primary electrons for $\mathrm{CdTe}(111)$. 


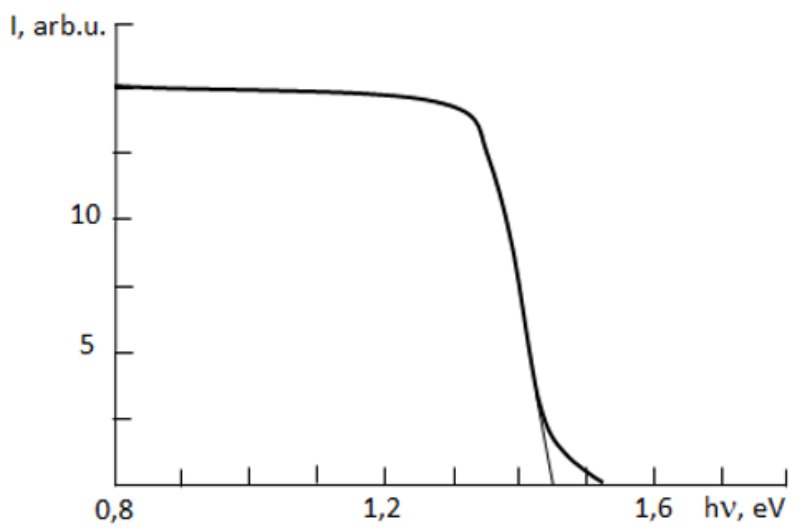

Fig. 4. The energy dependence of the intensity I of light transmitting through CdTe.

\section{Conclusion}

Thus, in this paper the nano-crystalline phases and nanofilms of CdBaTe and CdZnTe were formed and their band-energy parameters and the densities of occupied and free electronic states have been studied by the technique of low-energy ion implantation on the surface of single crystals $\mathrm{CdTe}(111)$.

\section{References}

[1] C.H. Lee, S.W. Park, Lee Jaesun, Y.M. Moon, et al., J. Electron. Mater. 27, 6, 668 (1998)

[2] A.V. Brodovoy, S.G. Bunchuk, Z.F. Tcibriy, FTT 53, 3, 524-526

[3] P.N. Tkachuk, FTT 42, 11, 1961-1963 (2000)

[4] K.D. Glinchuk, A.P. Medvid, A.M. Mychko, et al., FTP 47, 4, 435-441 (2013)

[5] N.I. Klyuy, V.B. Lozinskiy, A.N. Lukyanov, V.A. Morojenko, R.K. Savkina, et al., JTF 82, 8, 83-86 (2012)

[6] M.K. Herndon, A. Gupta, V.I. Kaydanov, R.T. Collins, Appl.Phys. Lett. 75, 3503 (1999)

[7] S.A. Muzafarova, Sh.A. Mirsagatov, J. Janabergenov, FTT 49, 6, 1111-1116 (2007)

[8] B.E. Umirzakova, D.A. Tashmukhamedovab, M.K. Ruzibaevaa, F.G. Djurabekova, S.B. Danaev, NuclearInstr.AndMehodsinPhys. Research Section B: Beam Inerac. WithMaterials and Atoms 326, 322-325 (2014)

[9] Y.S. Ergashov, D.A. Tashmukhamedova, B.E. Umirzakov, Journal of Surface Investigation 11, 2, 480-484 (2017)

[10] Z.E. Mukhtarov, Z.A. Isakhanov, B.E. Umirzakov, T. Kodirov, E.S. Ergashev, Technical Physics 60, 12, 1880-1884 (2015) 